\title{
Dissent over plans to build Indian neuroscience center
}

India is to establish a National Brain Research Centre (NBRC) to enable its scientists to compete on an international level in this major research field. The government Department of Biotechnology (DBT) plans to spend around $\$ 7$ million over the next four years on the new brain center, which will operate in a purpose-built facility at Gurgaon, 30 miles outside New Dehli.

Despite criticism from some leading Indian scientists that the money would be better spent elsewhere and that the entire effort is ego-driven, expatriate Indian researchers such as Abul Abbas, professor of pathology at Harvard Medical school, say that NBRC has the potential to make an important contribution to neuroscience and to Indian research in general. Abbas, who is a member of the external Standing Advisory Committee to the $\mathrm{DBT}$, believes that the main hurdle to success of the center is the recruitment of a foreigntrained director and staff. However, the problem is in persuading scientists to return to India where the monthly salary is around $\$ 400$, says Abbas.

The center will be headed by Prakash Tandon--one of India's most senior neurosurgeons who was trained abroad and is now retired. Tandon's appointment has stirred up a nest of parochial politics with former DBT advisory committee member Pushpa Bhargava claiming that NBRC is nothing but a scheme "to rehabilitate certain influential scientists after their retirement." Moreover, Bhargava says that brain research is in fact the responsibility of the Indian Council of Medical Research (ICMR) and not DBT."

ICMR chief, Nirmal Kumar Ganguly has defended DBT's stake in the venture and claims that although his council is not funding the NBRC, it will make all its research and clinical facilities available to its scientists. Around 60 million Indians are schizophrenic and study of this and other disorders of the brain will receive priority at the center.

Debabar Banerjee professor of community medicine of Jawaharlal Nehru University in Deihi also opposes the NBRC. "Creation of the brain research center is a typical example of how national health priorities get subverted to personal interests of a few individuals," he said, referring to Tandon. "It is ironic that while we sink millions of rupees to study the human brain, millions in the state of west Bengal are being poisoned by arsenic in drinking water. Why there is no similar effort to solve the arsenic problem?" asks Baneriee.

Replying to criticism about the relevance of brain research in a poor country, DBT secretary Manju Sharma insists that "funding has been kept down by trying to network existing facilities."

The 15 existing neuroscience facilities in the country will be networked with NBRC acting as the "hub." The human fetal bank in Delhi, the brain tissue bank, the neuroscience informatics center in Bangalore and primate facility for behavioral studies in Lucknow will be pooled and there are plans to create new centralized facilities for transgenic animals and modern equipment at the NBRC. A four-year scientific program has been drawn up which includes research on aging, memory, neuronal network, substance abuse, neural transplantation, cerebral malaria and tuberculosis meningitis.

The NBRC committee is currently trying to establish links with international researchers. A fellowship scheme has been agreed with the UK's Wellcome Trust to allow four of the center's scientists to be trained abroad each year.

K.S. Jayaraman, New Delhi

\section{Dengue fever on the increase}

Outbreaks of dengue fever, the most widespread vector-borne viral disease known, seem to be on the increase worldwide, causing physicians and public health officials to fret over ways to stem the pathogen's progress. While an epidemic of dengue around Rio de Janeiro continues to claim lives, a particularly deadly strain of the virus has been spreading in Puerto Rico and smaller outbreaks have occurred in Indonesia and Cambodia. Health officials in Phnom Penh estimate that the number of cases in Cambodia could reach 1,200 in August, which is peak season for Dengue fever.

While some of the disease's increased prevalence may be due to improved reporting and greater international attention to emerging infections, epidemiologists are nonetheless taking the situation seriously. "For reasons we don't fully understand, we have epidemics which occur periodically and each country has cycles of 3-5 years," explains Duane Gubler, director of Vector-Borne Diseases at the US Center for Disease Control and Prevention in Fort Collins. Gubler adds that the dengue- 3 strain found in Puerto Rico is especially troubling, since its 17 -year absence from the Americas has left most Caribbean populations highly susceptible to it. "We're anticipating that there will be an outbreak this year in Puerto Rico," Gubler says.

In Indonesia, where 36 people have died already this year compared with only ten in 1997, city officials are trying to control the outbreak by fumigation. However, experts are skeptical of this approach: "if there's an outbreak going on, by the time people get in there and spray you're usually on the downswing anyway," says Curtis Hayes, who heads the Division of Infectious Disease at the U.S. Naval Medical Institute. In addition, Aedes aegypti, the mosquito which carries the virus, is largely found in indoor areas inaccessible to sprays. "[Fumigation is] very costly, and it's very ineffective but it's popular because it's something that people can see is being done," asserts Gubler.

A handful of groups around the world are working to develop a vaccine against dengue, which would eliminate the need for such unproductive strategies. "It's an active area of research, [but] it doesn't seem like there will be a vaccine available in the next few years," states Hayes. One major problem is the potential of a vaccine to cause dengue shock syndrome, a condition in which exposure to one serotype of the virus may lead to a much more serious illness when another serotype is encountered. Alan Dove, New York 